\title{
ECC Refrigerator: Finish System Design of a Refrigerator Using an Electrochemical Compressor
}

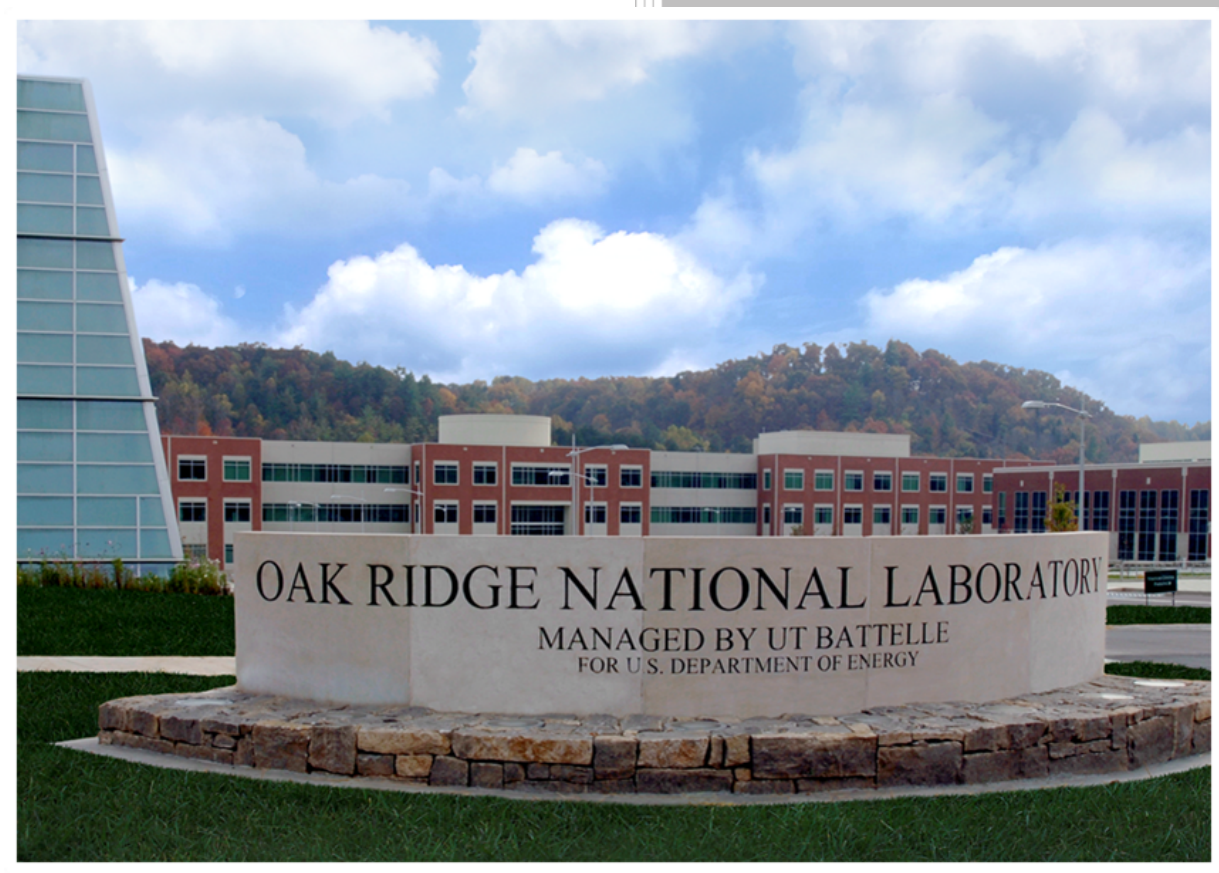

Bo Shen

Ayyoub Momen

Approved for public release.

Distribution is unlimited. 


\title{
DOCUMENT AVAILABILITY
}

Reports produced after January 1, 1996, are generally available free via US Department of Energy (DOE) SciTech Connect.

Website http://www.osti.gov/scitech/

Reports produced before January 1, 1996, may be purchased by members of the public from the following source:

\author{
National Technical Information Service \\ 5285 Port Royal Road \\ Springfield, VA 22161 \\ Telephone 703-605-6000 (1-800-553-6847) \\ TDD 703-487-4639 \\ Fax 703-605-6900 \\ E-mail info@ntis.gov \\ Website http://www.ntis.gov/help/ordermethods.aspx
}

Reports are available to DOE employees, DOE contractors, Energy Technology Data Exchange representatives, and International Nuclear Information System representatives from the following source:

Office of Scientific and Technical Information

PO Box 62

Oak Ridge, TN 37831

Telephone 865-576-8401

Fax 865-576-5728

E-mail reports@osti.gov

Website http://www.osti.gov/contact.html

This report was prepared as an account of work sponsored by an agency of the United States Government. Neither the United States Government nor any agency thereof, nor any of their employees, makes any warranty, express or implied, or assumes any legal liability or responsibility for the accuracy, completeness, or usefulness of any information, apparatus, product, or process disclosed, or represents that its use would not infringe privately owned rights. Reference herein to any specific commercial product, process, or service by trade name, trademark, manufacturer, or otherwise, does not necessarily constitute or imply its endorsement, recommendation, or favoring by the United States Government or any agency thereof. The views and opinions of authors expressed herein do not necessarily state or reflect those of the United States Government or any agency thereof. 


\title{
Building Technologies Research and Integration Center \\ BTO Project 3.2.2.26 \\ FY17 $3^{\text {rd }}$ Milestone Report
}

Finish System Design of a Refrigerator Using an Electrochemical Compressor

\author{
Authors \\ Bo Shen, Ayyoub Momen
}

Date: 10/31/2017

Prepared by

OAK RIDGE NATIONAL LABORATORY

Oak Ridge, TN 37831-6283

managed by

UT-BATTELLE, LLC

for the

US DEPARTMENT OF ENERGY

under contract DE-AC05-00OR22725 


\section{Finish System Design of a Refrigerator Using an Electrochemical Compressor (Regular)}

\section{Executive Summary}

The report depicts a refrigerator system design using electrochemical compression and metal hydride heat exchangers. It also introduces a novel heat exchanger design, aiming to solve the typical "dead mass" issue for heat exchangers containing solid particles.

\section{Introduction}

A metal hydride $(\mathrm{MH})$ alloy has a similar mechanism as phase change of a conventional refrigerant, where the MH doesn't change temperature at a given plateau pressure when absorbing/desorbing hydrogen. Major formation heat transfer occurs in this phase, i.e. called $\alpha+\beta$ phase. The figure below depicts the "saturation" temperature as a function of the plateau pressure for selected MH alloys suitable for electrochemical compression applications, reported in [1]. An electrochemical compressor will create low pressure at the suction side, resulting in a low temperature source and absorbing heat from a controlled environment; and high pressure at the discharge side leading to a high temperature sink, discharging heat to surrounding. Multiple choices of $\mathrm{MH}$ alloys having various pressure-temperature relationships facilitate wide applications, e.g. space cooling, water heating and refrigeration, etc.



Figure 1: Van’t Hoff plots for selected hydride-forming alloys suitable for H2 compression [1]

\section{System Diagram}

Figure 2 describes the system diagram of an initial electrochemical refrigerator design. The considerations are given as following,

1. The refrigerator has two coils exchanging heat with air, one coil is a glycol-to-air heat exchanger (C-to-A Coil) to absorb heat from the refrigerator cabinet, and the other is a water-to-air (W-to-A Coil) heat exchanger to discharge heat to the surrounding.

2. It has two metal hydride heat exchangers (MHHX). One low temperature MHHX is located at the suction side of the ECC compressor; the other high temperature MHHX is located at the discharge side. Inside the heat exchangers, MH powder exchanges heat with water or glycol flowing in coiled tubes.

3. The system has three pumps. Pump A circulates glycol from the low temperature MHHX's coiled tube to the C-to-A coil; Pump B circulates water from the high temperature MHHX's coiled tube to the W-to-A coil; and Pump C circulates water in the coil tubes of the two MHHXs. 
4. The ECC refrigerator has two working modes. The first is Pumping Mode, when the ECC compressor is energized, the bypass valve is closed, pumps A and B are on, and pump C is off. In this mode, the hydrogen will be moved from the low temperature MHHX to the high temperature MHHX, absorbing heat from the C-to-A coil and discharging heat to the $\mathrm{W}$-to-A coil. The second is Balance Mode, when the ECC compressor is off, the bypass valve is open, pumps A and B are off and pump $\mathrm{C}$ is on. In the case, hydrogen flows from the high temperature MHHX to the low temperature MHHX due to the pressure and temperature difference. Pump C circulates water between the coiled tubes in the two MHHXs and eventually leads to equal pressure and temperature. Balance Mode restores hydrogen concentration in the low temperature MHHX, and prepares the next Pumping Mode.

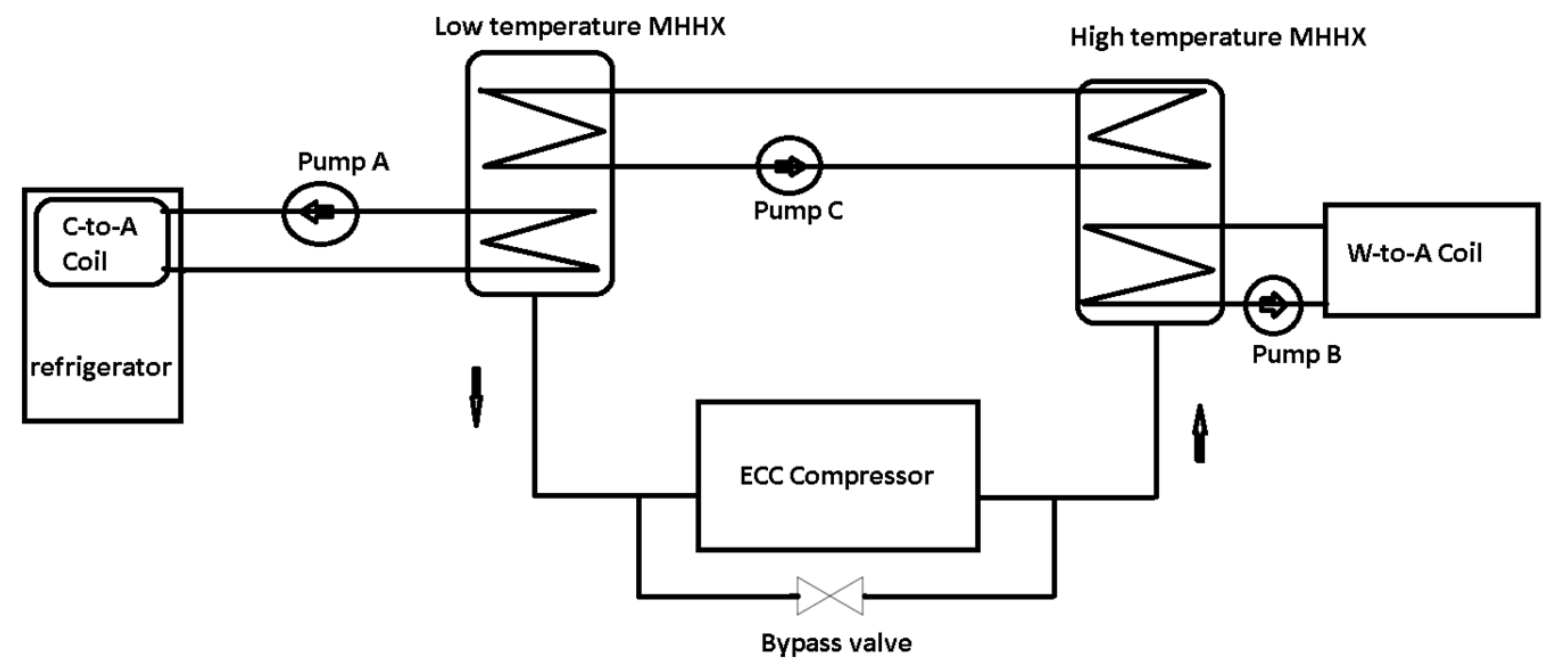

Figure 2: System Diagram of ECC Refrigerator with Metal Hydride Alloy

\section{Novel Design for Heat Exchangers Containing Solid Powder}

We developed an innovative metal hydride (MH) heat exchanger concept, and call it "up-down reversible heat exchanger", as depicted in the figure below. This design aims to solve the typical "dead mass" problem in heat exchangers containing solid particles like $\mathrm{MH}$ powder. In a regular MH heat exchanger, the "dead mass" contains MH powder, heat transfer tubes and container, which cycle heat between the absorption and desorption processes. The MH powder absorbs hydrogen and generates reaction heat, which heats up the container and tubes. After that, the powder desorbs hydrogen and absorbs heat. Before releasing useful cooling capacity, the tubes and container must be cooled down, this causes a big irreversibility. The new design will get rid of the "dead mass" due to the container and tubes. As shown in the figure, we will have a cylinder pressure vessel having coiled tubes at both ends. We will fill $\mathrm{MH}$ powder half-full in the cylinder. Cold glycol, carrying the cooling capacity, flows though the coiled tube at one end, i.e. "desorption end"; and hot glycol, removing the MH absorption reaction heat, flows through the coiled tube at the other end, i.e. "absorption end". The "desorption end" is connected to the suction port of an electro-chemical compressor, and the "absorption end" is connected to the discharge port. We will put the $\mathrm{MH}$ container in a vertical position, and switch the up and down positions by rotating it using a stepper motor. The $\mathrm{MH}$ powder will be moved by gravity from one end to the other, when the corresponding absorption/desorption process completes. In this way, we will always heat one end and cool the other end, and eliminate heat transfer losses through the heat exchanger metal parts. This will minimize the "dead mass" and reduce the cyclic loss in an electro-chemical cycle. 


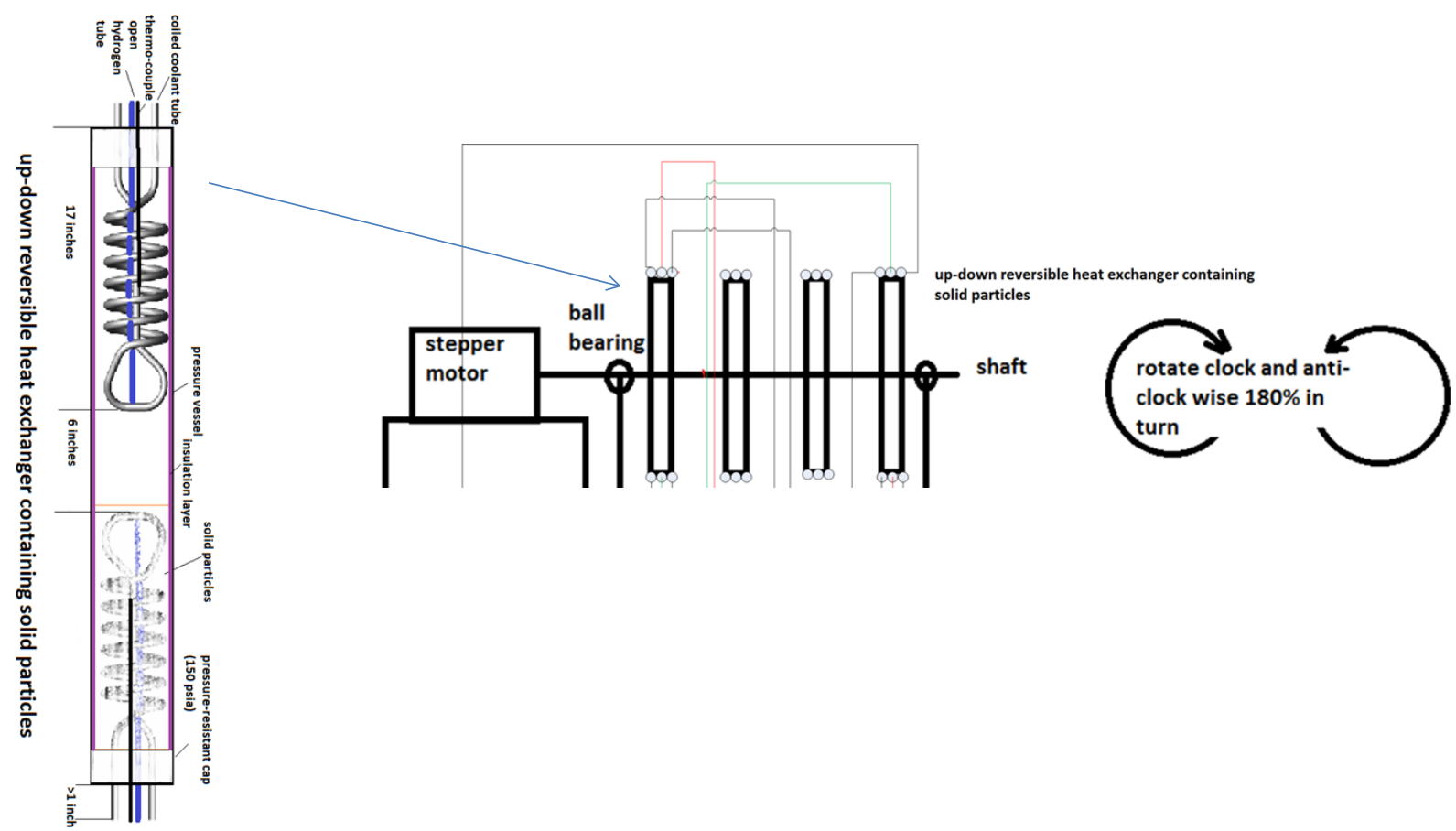

Figure 3: Operation of up-down reversible heat exchanger.

We fabricated two metal hydride (MH) heat exchangers, for coolant-to-MH powder heat transfer. The design is to put two coiled tubes (for coolant flow) at the two ends of a stainless steel vessel (photo below shows one coiled tube);



Figure 4: Coiled tube in metal hydride heat exchanger.

and have center tubes (with filter mesh cover, photos below) to feed and draw the hydrogen flow in the vessel.

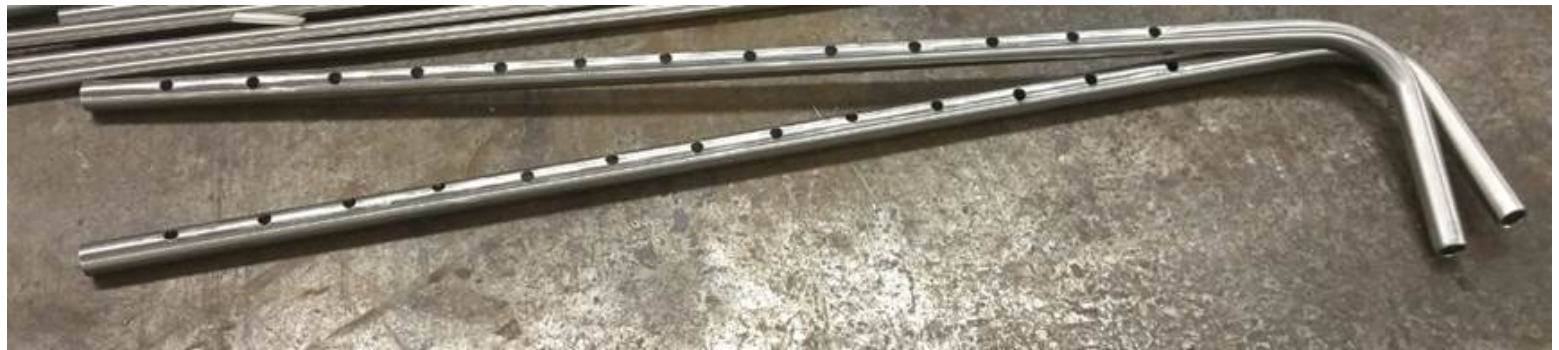

Figure 5: Center feeding/drawing tubes with holes. 


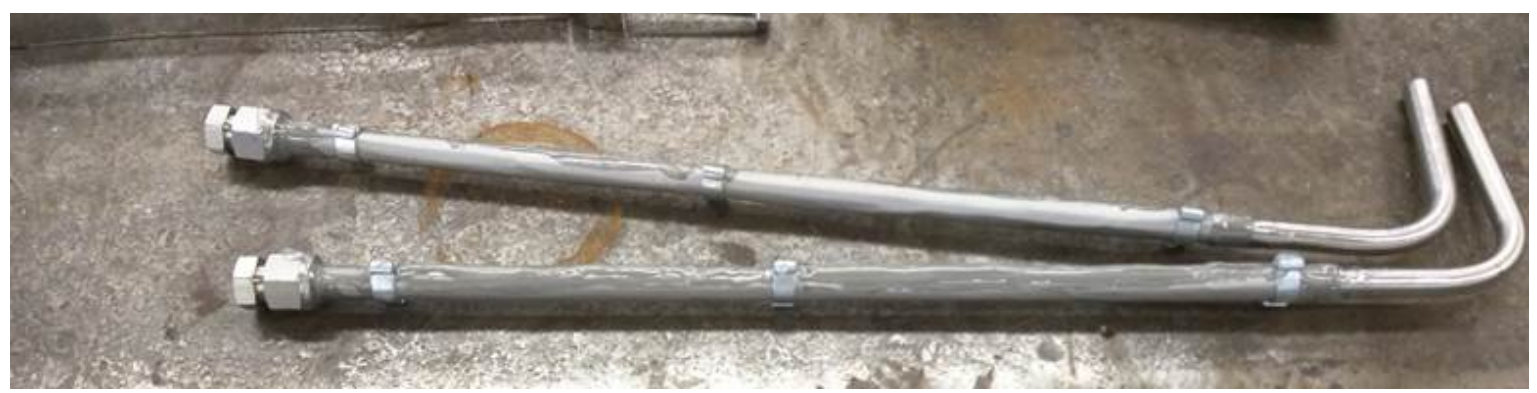

Figure 6: Center feeding/drawing tubes with filter mesh cover.

A photo of the full assembly with two center feeding/drawing tubes soldered in the middle and two coil tubes fastened at the two ends is shown below.

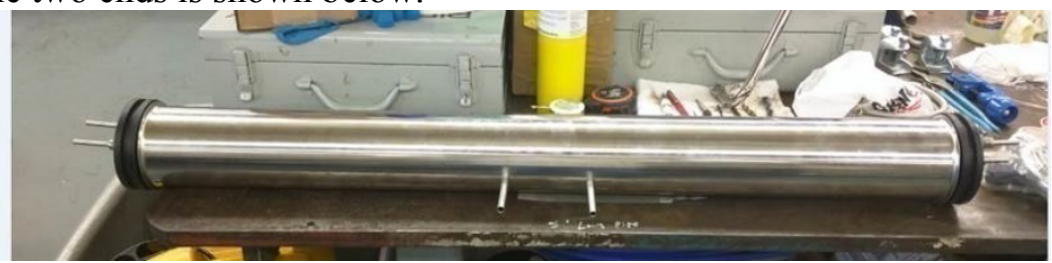

Figure 7: Assembled metal hydride heat exchanger.

We will fill the heat exchanger vessel with selected MH powder and connect the HXs to the hydrogen compressor and coolant flow. During the operation, we will rotate or shake the heat exchanger to accelerate mixing and heat transfer of the $\mathrm{MH}$ powder.

\section{References}

[1] M.V. Lototskyy, V.A. Yartys, B.G. Pollet, R.C. Bowman, Metal hydride hydrogen compressors: A review, In International Journal of Hydrogen Energy, Volume 39, Issue 11, 2014, Pages 5818-5851, ISSN 0360-3199, https://doi.org/10.1016/j.ijhydene.2014.01.158. 